\title{
Cooperation in Negotiation Is the Way to Creativity: A Case from the Royal Commission Yanbu Colleges and Institutes
}

\author{
Hassen Hussain Altalhi ${ }^{1}$, Shaysh Nazzal Alshammri² \\ ${ }^{1}$ Management Science Department, Yanbu University College, Yanbu Industrial City, KSA \\ ${ }^{2}$ Business Administration School, Northern Border University, Arar City, KSA \\ Email: altalhih@rcyci.edu.sa, shaysh.Alshammri@nbu.edu.sa
}

How to cite this paper: Altalhi, H.H. and Alshammri, S.N. (2018) Cooperation in Negotiation Is the Way to Creativity: A Case from the Royal Commission Yanbu Colleges and Institutes. Journal of Human Resource and Sustainability Studies, 6, 149-156. https://doi.org/10.4236/jhrss.2018.61033

Received: November 25, 2017

Accepted: December 7, 2017

Published: March 29, 2018

Copyright $\odot 2018$ by authors and Scientific Research Publishing Inc. This work is licensed under the Creative Commons Attribution International License (CC BY 4.0).

http://creativecommons.org/licenses/by/4.0/

\begin{abstract}
This research aims to find whether cooperative negotiation style impacts creativity, productivity, work commitment and socialization in organizations. The data were collected by a survey distributed to employees of The Royal Commission Yanbu Colleges and Institutes, Saudi Arabia. The number of participants is 103. The results show that cooperative negotiation style has an influence on creativity only. In addition, age and experience are not correlated with cooperative negotiation style or other variables. However, experience has an influence on productivity. The results add a significant aspect of cooperative negotiation style to the literature.
\end{abstract}

\section{Keywords}

Cooperative Negotiation Style, Competitive Negotiation Style, Creativity, Productivity, Socialization

\section{Introduction}

Negotiation is one of conflict resolution approaches used to resolve conflicts between parties, whether individuals or organizations [1]. In negotiation, disputants have an opportunity to discuss directly their positions and interests. Negotiation occurs frequently where issues are negotiated daily at home, work, etc. It is considered the popular approach of dispute settlement [2]. However, it does not mean that every negotiation would end up with solutions that meet parties' interests. [3] explains that not all conflicts could be resolved by negotiation. It depends on complexity of an issue and a desire of disputants toward cooperation. This necessitates an intervention of such a third party as mediator, facilita- 
tor or arbitrator.

[2] states that two or more parties could be included in negotiation process. This relates to how many parties are concerned by such an issue. Regardless of number of parties involved, negotiation is regarded a process where it is conducted through stages. [3] explains that negotiation has different stages where parties need first to identify their needs and their counterparts' needs, discuss an issue, and finally close a discussion.

In negotiation, parties may adopt one of two approaches: cooperation or competition [4]. These approaches differ in terms of behaviors, tactics, and outcomes, as would be explained more in the literature. This research focuses on how adopting cooperative negotiation styles may positively affect various aspects of workplace. This assists in understanding behaviors of employees when negotiating disputes in work, which is essential for human resource and personnel affairs in organizations.

\section{Literature Review}

Negotiation skills in today's professional environment are considered to be an essential and powerful tool which can make individuals more productive and successful in their professional careers. As mentioned by [1], negotiation is an important skill for any person such as managers, leaders, employees, and customers. Negotiation skills are not only restricted to workers in organizations but also to individuals in their daily lives to manage or resolve conflicts when they arise. Numerous studies define negotiation in different contexts. Negotiation, according to [5], is a communication skill which requires persuasive communication. Thus, negotiation focuses on relationship between conflicting parties in which the needs of both sides can be fulfilled mutually as much as possible. As mentioned earlier, negotiation approaches fall into two categories: cooperation and competition.

According to [6] and [7], a cooperative strategy is viewed as integrative bargaining in which a win-win settlement is generated. [8] indicates that cooperative style is related to effective communication. Individuals who are influenced by cooperative style are less likely to have problems in communication and understanding each other. Likewise, [9] argue that individuals who embrace cooperative style in negotiation are more likely to respond with same behavior. [10] emphasized that individuals usually cooperate with others in negotiation when they have a desire to work with others. Also, a collaborative strategy is utilized to enhance long-term relationships in which conflicting parties are expected to maintain their relationship in future [11].

A competitive negotiation style, however, is viewed as the opposite of cooperative negotiation style. [12] described competitive style as a behavior where an individual cares for oneself in a way that s/he wants to gain even if that at expense of other party (win-lose).

As mentioned by [6], competitive tactic is a win-lose settlement. Unlike coop- 
erative strategy, competitive approach is correlated with distributive scenarios in which outcomes are zero-sum. In this regard, competitive individuals expect that an incompatible party shares the same view and then act distributively irrespective of other party involved.

According to [12], competitive style is related to high assertiveness and low cooperativeness whereas collaborative style is associated with low assertiveness and high cooperativeness. Competitive style focuses on fulfilling one's needs and desires without taking into account wishes of other party. On the contrary, collaborative style recognizes needs of both parties and aims to satisfy their wishes. In term of relationships, [11] indicates that competitive strategy is employed only in a short-term relationship in which conflicting parties are not expected to maintain their relationship any more.

From the literature, we understand how collaborative negotiation style differs from competitive negotiation style regarding behaviors and outcomes. The literature also clarified that collaborative negotiation style assists in improving relationship between conflicting parties, and reaching win-win outcomes. However, there is a need to measure how cooperative negotiation style may affect essential aspects of work such as productivity, creativity, commitment, and socialization. These aspects are very important as they relate to practical and psychological aspects of employees in organizations. Negotiating conflicts occur frequently in workplace; thus, organizations should be aware how adopting cooperative negotiation style would affect theses aspects.

Productivity is considered lifeblood of organizations. According to [13], productivity is essential for increasing revenue and reducing costs. Thus, it is important for organizations to be mindful that productivity of employees is influenced by an organization's climate. [14] elaborates on how productivity in organizations is affected by social and physical aspects of environment.

As for creativity, it is simply defined as inventing new ideas and things [15]. It is necessary that employees be creative as it will reflect on performance of organization as a whole. However, there are many factors which affect creativity in organization. [16] explains that creativity is affected by job stress. [17] also says that creativity is influenced by climates prevailing in an organization as well as the organization's culture. Furthermore, [18] states that emotions could affect creativity negatively or positively; it depends on how an organization deals with employees' emotions in terms of expression and encouragement.

Finally, socialization (relationship \& association between employees) and work commitment are very important factors, affecting performance of organizations. [19] mentions that researchers emphasize the importance of friendship for productivity and development in workplace. When employees build relationship with each other, cooperation in work would increase among them. As for commitment in work, it is important for productivity. Employees who pledge to instructions and policy of work would certainly be productive compared with those who are not disciplined. 


\subsection{Research Question}

Does an increase of cooperation in negotiation lead to an increase in creativity, productivity, commitment in work, and socialization?

\subsection{Hypotheses}

H1: There is a significance relationship between cooperative negotiation style and creativity.

$\mathrm{H} 2$ : There is a significance relationship between cooperative negotiation style and productivity.

H3: There is a significance relationship between cooperative negotiation style and work commitment.

H4: There is a significance relationship between cooperative negotiation style and socialization in work.

\section{Methodology}

This study was conducted by using quantitative approach, and the data was collected through a survey. The results show that overall Cronbach's alpha value is 0.773 which is above the standard value $(0.70)$. The data was analyzed using SPSS.

For collecting data, the survey was distributed randomly to employees in The Royal Commission Yanbu Colleges and Institutes, Saudi Arabia, and the number of the participants were 103. The ages of participants ranged from 25 years-old to 58 years-old as shown in Table 1 . The average of experience of participants is 17 years.

The survey contained 19 questions which measure negotiation style, productivity, creativity, work commitment, and socialization. The first four questions were related to negotiation style, the questions from 5 to 7 related to productivity, the questions from 8 to 11 related to productivity, the questions from 12 to 15 related to work commitment, and the questions from 16 to 19 related to socialization. There were five answers for each question where each answer given a number: Always (5), Usually (4), Sometimes (3), Rarely (2), and Never (1). For each participant, the average of points of the questions was calculated for each category separately (cooperative negotiation style, productivity, creativity, work commitment, and socialization). Then, the relationship between cooperative negotiation style and all other variables were measured separately, by correlation coefficient as shown in Table 2.

\section{Analysis and Discussion}

The data shows that the degree of cooperation among participants varies, which is used as an independent variable. The results show that age and experience are not correlated with cooperative negotiation style. Many may think that when individuals get older or get more experience, they become more cooperative in negotiation as they get used to dealing with disputes in workplace. However, 
Table 1. Descriptive statistics.

\begin{tabular}{cccccc}
\hline & $\mathrm{N}$ & Minimum & Maximum & Mean & Std. Deviation \\
\hline Age & 103 & 25.00 & 58.00 & 42.8738 & 8.05213 \\
Experience & 103 & 0.00 & 35.00 & 17.0583 & 8.30878 \\
Cooperative Style & 103 & 2.75 & 5.00 & 4.2524 & 0.44349 \\
Creativity & 103 & 3.00 & 5.00 & 4.3172 & 0.52472 \\
Productivity & 103 & 2.50 & 5.00 & 4.6286 & 0.40351 \\
Commitment & 103 & 2.50 & 5.00 & 4.6796 & 0.41335 \\
Socialization & 103 & 3.00 & 5.00 & 4.5194 & 0.47446 \\
Valid N (listwise) & 103 & & & \\
\hline
\end{tabular}

Table 2. Correlations.

\begin{tabular}{|c|c|c|c|c|c|c|c|c|}
\hline & & Age & Experience & Cooperative Style & Creativity & Productivity & Commitment & Socialization \\
\hline \multirow{3}{*}{ Age } & Pearson Correlation & 1 & $0.921^{* *}$ & 0.132 & -0.029 & 0.131 & 0.172 & 0.114 \\
\hline & Sig. (2-tailed) & & 0.000 & 0.184 & 0.770 & 0.187 & 0.083 & 0.253 \\
\hline & $\mathrm{N}$ & 103 & 103 & 103 & 103 & 103 & 103 & 103 \\
\hline \multirow{3}{*}{ Experience } & Pearson Correlation & $0.921^{* *}$ & 1 & 0.117 & 0.029 & $0.205^{*}$ & 0.183 & 0.185 \\
\hline & Sig. (2-tailed) & 0.000 & & 0.239 & 0.768 & 0.038 & 0.064 & 0.061 \\
\hline & $\mathrm{N}$ & 103 & 103 & 103 & 103 & 103 & 103 & 103 \\
\hline \multirow{3}{*}{ Coop Style } & Pearson Correlation & 0.132 & 0.117 & 1 & $0.400^{* *}$ & 0.118 & 0.128 & 0.140 \\
\hline & Sig. (2-tailed) & 0.184 & 0.239 & & 0.000 & 0.235 & 0.198 & 0.160 \\
\hline & $\mathrm{N}$ & 103 & 103 & 103 & 103 & 103 & 103 & 103 \\
\hline
\end{tabular}

${ }^{\star}$ Correlation is significant at the 0.05 level (2-tailed); ${ }^{*}$ Correlation is significant at the 0.01 level (2-tailed).

there is no significant relation shown in this research as demonstrated in Table 2.

The first hypothesis is accepted, so there is a relationship between cooperative negotiation style and creativity. The more participants cooperate in negotiation, the more they become creative. The correlation is 0.400 which is significant at 0.01 level (2-tailed). In the literature, we find that the level of creativity is affected by organization's climate [17] and job stress [16]. This indicates that emotions play a negative role in creativity. Individuals who adopt cooperative negotiation style are less likely to be emotional. Accordingly, they become more stable and rational which leads to creativity. On the other hand, individuals who compete in negotiation usually get emotional because competition escalates conflicts, and conflict creates unpleasant feelings such as stress [16]. As for age and experience, they do not have an influence on creativity.

The second hypothesis which relates to cooperative negotiation style and productivity is rejected as there is no significance correlation between the two variables. Productivity could be affected by work environment as [14] explains. Usually, when employees feel satisfied and comfortable, they tend to be more 
productive. [20] conducted a study on factors which impact percieved productivity of Egyptians teleworkers. They found that productivity of workers could be affected by various variables such as employees' satisfaction and flexibility in work. Moerover, [21] argue that individuals having positive emotions such as relief are more productive than their counterparts who having negative emotions. However, this research does not show any correlation between productivity and cooperative negotiation style (the correlation is significant neither at level 0.01 nor at level 0.05). Instead, the results show that there is a relationship between experience and productivity, the correlation is 0.205 which is significant at the 0.05 level (2-tailed). The more employees stay in an organization, the more their productivity increases. On the contrary, age is not correlated with productivity. There is no significant evidence that older participants are more productive than young participants.

As for work commitment, [22] explains that commitment in workplace is considered one of the essential factors related to organizational performance. $\mathrm{He}$ adds also that commitment to work has mutual affects with style of management (climate and structure) and incentives system. In addition, it seems logically that those who are flexible and cooperative tend to obey rules and consider objectives of organizations (more committed). However, this research shows that cooperative negotiation style does not affect commitment to work, so the third hypothesis is rejected. Participants who show high levels of cooperation are not more committed than those who show low levels of cooperation. In addition, there is no significant evidence that age or experience has an influence on work commitment.

As for socialization, this research shows that there is not significant evidence that the more individuals cooperate in negotiation, the more they tend to build relationship with others, which means that the fourth hypothesis is rejected. Individuals who have cooperative behaviors in negotiation, do not show a desire to build relationship more than their counterparts who have low cooperative behavior. On the other hand, socialization is correlated with neither age nor experience. Even though these two variables have influence on behaviors of employees generally; this research does not show any correlation between them.

\section{Implication, Future Research, \& Limitation}

The implication of this research is mainly in organizational behavior. It assists in understanding how cooperative negotiation style impact behaviors of employees, which is very important for managements in organizations. It shows that adopting cooperative behavior in negotiation leads to creativity, and also experience is correlated with productivity. The implications also extend to negotiation outside organizations since styles of individuals in negotiating inside and outside organization is almost the same as it relates to behaviors of individuals. Moreover, the implication is important in mediation as well. The mediators need to be aware that encouraging disputants to be cooperative in negotiation assist in reaching 
creative solutions.

Future research needs to be conducted on how cooperative negotiation style might influence other aspects related to management in organizations such as leadership, rationality, where the research should target managers and decision makers. This would assist in more understanding of the effect of cooperative negotiation style on organization. As for limitation, this research was conducted in a Saudi organization; so, it might be difficult to generalize the results to other organizations in other countries. Organization's culture differs from one organization to another, according to norms and values prevailing in societies to which organizations belong.

\section{Summary}

In general, cooperative negotiation style assists in improving relationships between employees and reaching win-win outcomes, in contrast to competitive negotiation style. This research reveals new facts about cooperative negotiation style. It shows how cooperative negotiation style impacts creativity. Organizations should work hard to train employees how to be cooperative in negotiation as this will enhance creativity which would reflect positively on performance of organizations. However, there is no significance evidence that cooperative negotiation style impacts productivity, socialization, and commitment in work. Yet, productivity is affected by experience.

\section{References}

[1] Luecke, R. (2010) Best Practice Workplace Negotiations. EBook Edition, American Management Association, Florida.

[2] Schellenberg, J.A. (1996) Conflict Resolution: Theory, Research, and Practice. State University of New York Press, Albany, NY, USA.

[3] Churchman, D. (1995) Negotiation: Process, Tactics, Theory. 2nd Edition, University Press of America, Lanham, Maryland.

[4] Wilmot, W.W. and Hocker, J.L. (2007) Interpersonal Conflict. 7th Edition, McGraw-Hill, Boston.

[5] Forsyth, P. (1997) Conducting Effective Negotiations: How to Get the Deal You Want. How to Books Ltd., Oxford.

[6] Lewicki, R.J., Barry, B. and Saunders, D.M. (2011) Essentials of Negotiation. McGraw-Hill/Irwin, New York.

[7] Adler, R.B. and Elmhorst, J.M. (2008) Communicating at Work: Principles and Practices for Business and the Professions. McG, New York.

[8] Spangler, B. (2003) Win-Win, Win-Lose, and Lose-Lose Situations. Beyond Intractability. In: Burgess, G. and Burgess, H., Eds., Conflict Information Consortium, University of Colorado, Boulder.

[9] Kelley, H.H. and Stahelski, A.J. (1970) Social Interaction Basis of Cooperators' and Competitors' Beliefs about Others. Journal of Personality and Social Psychology, 16, 66-91. https://doi.org/10.1037/h0029849

[10] Ewoldsen, D.R., Eno, C.A., Okdie, B.M., Velez, J.A., Guadagno, R.E. and DeCoster, J. (2012) Effect of Playing Violent Video Games Cooperatively or Competitively on 
Subsequent Cooperative Behavior. Cyberpsychology, Behavior and Social Networking, 15, 277-280. https://doi.org/10.1089/cyber.2011.0308

[11] Johnston, R.W. (1982) Negotiation Strategies: Different Strokes for Different Folks. Personnel, 59, 36-45.

[12] Thomas, K.W. (1976) Conflict and Conflict Management. In: Dunnette, M.D., Ed., Handbook of Industrial \& Organizational Psychology, Rand McNally, Chicago, 889-935.

[13] McCallum, J.S. (2000) Advocating Productivity. Ivey Business Journal, 64, 38-41.

[14] Mathew, J. (2007) The Relationship of Organisational Culture with Productivity and Quality: A Study of Indian Software Organisations. Employee Relations, 29, 677-695. https://doi.org/10.1108/01425450710826140

[15] Gaut, B. (2010) The Philosophy of Creativity. Philosophy Compass, 5, 1034-1046. https://doi.org/10.1111/j.1747-9991.2010.00351.x

[16] Hon, A.H. and Lui, S.S. (2016) Employee Creativity and Innovation in Organizations: Review, Integration, and Future Directions for Hospitality Research. International Journal of Contemporary Hospitality Management, 28, 862-885. https://doi.org/10.1108/IJCHM-09-2014-0454

[17] Andriopoulos, C. (2001) Determinants of Organisational Creativity: A Literature Review. Management Decision, 39, 834-840. https://doi.org/10.1108/00251740110402328

[18] Lofy, M.M. (1998) The Impact of Emotion on Creativity in Organizations. Empowerment in Organizations, 6, 5-12. https://doi.org/10.1108/14634449810208105

[19] Chen, C.-Y., Mao, H.-Y. and Hsieh, A.-T. (2012) Role Ambiguity, Employee Gender, and Workplace Friendship. Psychological Reports, 110, 719-730.

https://doi.org/10.2466/01.07.21.PR0.110.3.719-730

[20] Aboelmaged, M.G. and El Subbaugh, S.M. (2012) Factors Influencing Perceived Productivity of Egyptian Teleworkers: An Empirical Study. Measuring Business EXcellence, 16, 3-22. https://doi.org/10.1108/13683041211230285

[21] Hellriegel, D. and Slocum, J.W. (2009) Organizational Behavior. 12th Edition, South-Western Cengage Learning, Mason, $\mathrm{OH}$.

[22] Fink, S.L. (1992) High Commitment Workplaces. Quorum Books, New York. 